\title{
Ceramic Units Manufactured by Additive Technologies: the Problem of Final Product Porosity. A Brief Review
}

\author{
V.G. Konakov ${ }^{1,2}$,A.V.Soudarev ${ }^{3}$, O.Yu. Kurapova ${ }^{1,2}$ and I.Yu. Archakov ${ }^{1,4}$ \\ ${ }^{1}$ Scientific and Technical Center "Glass and Ceramics", ul. Dudko 3, St. Petersburg, 192029, Russia \\ ${ }^{2}$ Saint Petersburg State University, 7/9 Universitetskaya nab., St. Petersburg 199034, Russia \\ 3“'Boyko Center", ul. Dudko 3, St. Petersburg, 192029, Russia \\ ${ }^{4}$ ITMO University, 49 Kronverksky Pr., St. Petersburg, 197101, Russia
}

Received: November 16, 2019

\begin{abstract}
The paper reviews the additive technologies application for the ceramic products manufacturing. Advantages and drawbacks of current approaches are mentioned; it is shows that the porosity of the final ceramic product is one of the main problems preventing the wide use of such ceramics at extreme exploitation conditions: high temperature and chemically aggressive gas ambience. A possible pathway to solve this problem is suggested: it is shown that chemical impregnation could provide significant porosity decrease coupled with mechanical properties increase.
\end{abstract}

\section{INTRODUCTION}

Nowadays, additive technologies (AT) are widely used to produce polymer units; modern equipment and wellknown approaches provide cost-effective results. AT application to metal units manufacturing $[1,2]$ needs production facilities with much higher cost; specific requirements are also stated for metal powders as a raw material for such technology. As a result, modern application of AT for the metal units production is rather limited, usually, it is restricted by industries producing hightech and high cost products: air/space, naval, etc. As for AT applications for ceramic units production (in this review we'll generally focus on some modifications of Selective Laser Melting technique in its different versions), these approaches are still at $\mathrm{R} @ \mathrm{D}$ step due to some principal problems originating from the nature of the material. Generally, these problems can be summarized as follows.

(i) High energy required to produce ceramics via conventional synthesis pathways resulting in specific requirements to laser equipment. Indeed, current tendencies in metal units production are the use of ultra- short laser impulses coupled with an extra-high energy of the beam. In doing so, the prototyping rate can be increased. Comparing to metals, ceramics possesses a number of significant advantages at high temperatures and in aggressive chemical ambience due to its chemical and temperature resistivity. The flip side of these benefits is much higher melting temperature of such a ceramics; to obtain it, one should significantly increase the laser power. In addition, specific requirements of heating and cooling during the ceramics manufacturing (usually, the high quality of the material is incompatible with fast heating/cooling) make the task quite more complicated: following conventional approaches, it is desirable to use a variable power of laser impact or some multi-laser system with one laser for material pre-heating and another one for melting. In addition, the above requirements makes preferable the use of partially defocused laser beam providing the larger surface of the powder material involved in the synthesis. So, more complicated laser system consisting of more powerful lasers should be used here.

(ii) Relatively low density of raw materials. The density of ceramics is usually 2-3 times lower than that typi-

Corresponding author: V.G. Konakov, e-mail: glasscer@yandex.ru 
cal for metals. So, the conventional approaches widely used for metal powders as raw materials for metal units production are rather questionable for ceramic powders. Just a few examples of such problems are discussed below. Generally, the use of powders containing spherical particles with the mean diameter being less that 8-10 $\mu \mathrm{m}$ provides excellent results in AT application for metal units production. However, the particles spherical shape, being evident preferable and quite achievable result for single metal and alloy powders, can be hardly achieved for ceramic powders used in AT. Some emphasis could result in more uniform mean particle size distribution and lower linear dimensions of the ceramic powder particles, but the spherical shape of the particle is, generally, not available due to milling step that is widely used in raw materials pretreatment. As for the particle size, operations with metal powders with $5 \mu \mathrm{m} \varnothing$ particles are currently widespread. In turn, some ceramic particles of similar dimensions could be easily moved on the working surface due to typical additive technology operations: surface leveling, inert gas pumping, and, even, under the impact of the laser beam. In turn, such powder particles displacement negatively affects the production process resulting in working surface deviations and, sometimes, dust pollutions in the atmosphere of the working chamber. So, the minimal linear size of ceramic powder particles should be at least two-three times higher. The same difference in the material density results in the fact that the use of roller (preferably, nonmetal one) is quite more effective for surface leveling and compacting here instead of the blade typically used in the case of metal powders. Thus, the difference in materials nature here also causes the technology changes.

(iii) The production of final units with the exact dimensions within the accuracy limits necessary for technological application is very difficult due to significant shrinkage typical for most ceramics manufacturing approaches. Generally, conventional ceramics production process includes the "green detail" step at which the desirable shape and size of the ceramic product are formed. The further step is a high-temperature treatment that converts the "green detail" into the final ceramics; typically, this process is accompanied by a significant shrinkage reaching percents of linear dimension changes. As an example, zirconia-based ceramics can be mentioned: the shrinkage at the conversion to final ceramics step can exceed 10-12\% here. Regretfully, this shrinkage can not be adequately computed till now; the attempts to manufacture a "green detail" with the shape providing the required geometry of the final ceramic product are successful for simple units shape only. At that, final laborious and expensive diamond cutting is usually necessary. The basic advantage of additive tech- nologies is the possibility to manufacture units with complex internal geometry (e.g., heat exchangers for ceramic microturbines characterized by the developed network of internal spiral channels); surely the problem of exact final product geometry is a key one here since no final mechanical treatment is possible for internal surfaces.

(iv) High porosity of the final ceramics preventing its usage under high temperature/chemically aggressive ambience conditions where the preferences of ceramics over all other materials are evident. Generally, ceramics is a porous material, even in case of vacuum tight ceramics, its density is $\sim 97 \%$ of the theoretical one. The porosity providing $85-90 \%$ of the theoretical density is considered as a good result for ceramics manufactured within the conventional approaches. In case of additive technologies application, this problem evidently manifests itself since the approach is based on surface binding (partial melting that involves a selected number of surface layers) instead of the whole bulk melting. On the other hand, the engineering requirements stated for the final ceramic products intend the minimal porosity level.

Thus, summarizing the specific requirements for AT process of ceramic units manufacturing, one can conclude that they originate from the nature of the material; hence, technical decision successfully used in metal units production can not be used here. A number of approaches for AT ceramic units production is now developed, let us briefly describe them.

The very first one suggested was based on the principle similar to polymer units production and implied the use of some liquid-phase raw material hardened under laser impact, in case of ceramics such a raw material was a slurry. This approach was developed in LaserApplicationCenter (LAC) of Technische Universität Clausthal, one can found some results of its application in, e.g., [3,4]. In some sense, this approach can be considered as being an analogue of the traditional pottery. The general idea here is the evaporation of a liquid fraction from the slurry under the laser heating coupled with some material baking; the result is the formation of a solid ceramic unit. This approach possesses a number of obvious advantages: its technique is comparatively simple, laser power required here is fairly low, while the sintering rate is rather high. In addition, raw materials are very cheap. So, the above discussed problems dealing with the requirements to laser system and raw material density are solved here. Regretfully, the slurry-based approach results in a great shrinkage at the step of the "green detail" conversion into the final ceramic product: the deviation of the linear dimensions here usually exceeds $10 \%$. Obviously, the optimization of the slurry composition will result in the 
decrease in such a deviation down to 5-7\%; however, this value is still fairly high. Another drawback of the approach is a significant porosity of the final ceramics; as a result, the mechanical strength of the manufactured ceramics is usually rather low. So, the discussed technology can be considered as a cheap and fast possibility to produce simple shape ceramic units that will be exploited at low temperatures and mechanical impacts.

The idea of the second approach is to use some organic-inorganic binder to fasten the layers of the raw material particles; see "3DSystems" patent [5], the review by Thierry Chartier et al. [6], and some references therein [7-9]. Ceramic powder with the required particle size distribution is used as a raw material here; each particle is covered by an ultrathin layer of some organicinorganic (e.g. resin-silica binder) compound acting as some glue. Under the proper impact (in our case, at laser beam irradiation), this glue hardens and connects these particles. This approach possesses a number of advantages. First, the basic task of the laser system here is the binding irradiation; hence, rather simple laser systems with a reasonable laser power can be used. Second, the use of organic-containing binder partially solves the problems with a raw powder density; it should be noted that it also makes possible some decrease in the powder particle size. In addition, a wide variety of the ceramic powders can be used as raw materials. However, the most important result here is the possibility to avoid shrinkage; indeed, no phase transformation (partial melting of a number of surface layers) takes place, so, the geometry deviations are limited by negligible changes in the thin binding layer thickness dimensions. On the other hand, the presence of organics in the final product restricts the temperature range of the final product exploitation as well as the chemical resistivity of the product. This problem is usually solved by high temperature exposure resulting in almost complete burning of the organic phase and chemical interactions of the binder's inorganic phase with the initial ceramics matrix. However, the general problem here is the binding layer thickness: the use of ultrathin binding layers gives rise to low mechanical properties of the material, while the roughening of these binding layers results in significant changes in the unit geometry due to shrinkage/ oxidation processes during the binder melting, the porosity of the final product also increases. Summarizing the above consideration, one can conclude the discussed approach as being very perspective, however, the porosity of the final product is still a problem here.

The direct laser melting was tested by W. Meinors and Y.-C. Hagedorn in Fraunhofer Institute for Laser Technology, see e.g. [10,11]. This approach is based on the increase in the laser heating power leading to partial melting of the surface of ceramic powder particle during the process. Generally, this technique can provide the necessary strength and heat resistance of the ceramic units produced; but it also faces some principle problems. Let us mention a number of them. First, the complex laser system with high power lasers is necessary here. At that, the specific features of the selective layer melting do not provide proper heating/cooling conditions that can eliminate thermal stress defects appearing during the melting process; these stresses are necessarily inherited by the bulk of the synthesized unit. It turn, this fact gives rise to inevitable cracking in the unit bulk leading to its partial or even complete destruction. Second, particle dimensions are drastically changed during the surface melting; as a result, the significant shrinkage takes place making impossible the production of the ceramic units with exact required geometry. On the other hand, the use of partial particles melting provides low porosity of the final products. So, the discussed seems to be rather effective in terms of porosity; however, some serious problems prevent its wide application at the moment.

An alternative approach was suggested by V. G. Konakov and A.V. Soudarev, see, e.g. [12,13]. A general idea of this pathway can be described as follows: metalceramic composition based on $\mathrm{Al}-\mathrm{SiC}-\mathrm{B}-\mathrm{BN}$ (In, Ga) system is used as a raw material (see [14] for more detail). This metal-ceramic powder is mechanically activated; laser impact applied during AT process gives rise to the onset of alumothermal reactions. In doing so, a "green" metal-ceramic unit is produced, it possesses mechanical properties enough for further mechanical pre-treatment (usual metalworking machines with carbide-tipped tools can be used here). At the next step, "green" metal ceramics is converted into final ceramics through high temperature oxidation/nitridization. The principle feature of this step is the maintaining of the unit geometry within $+0.3 \%$ limit, i.e. no shrinkage occurs during metal ceramics to final ceramics conversion, see [15-17] for more detail. The discussed approach provides an opportunity to solve most of the above mentioned problems typical for AT processes of ceramics production: laserinduced reactions overcome the limitations dealing with laser equipment; technical problems with raw materials density are solved by metal-ceramics usage; non-shrinkable metal-ceramics to ceramics conversion provides proper final unit geometry. However, the porosity problem was not still resolved within the use of this method. This statement can be illustrated by the X-ray tomography [18] data, it was used to investigate the final ceramics porosity in [19], rather high porosity level of $\sim 30$ vol.\% was shown.

Thus, summarizing the application of AT technologies to the ceramic units production, we can state that the porosity of the final product is one of the basic 
(a)
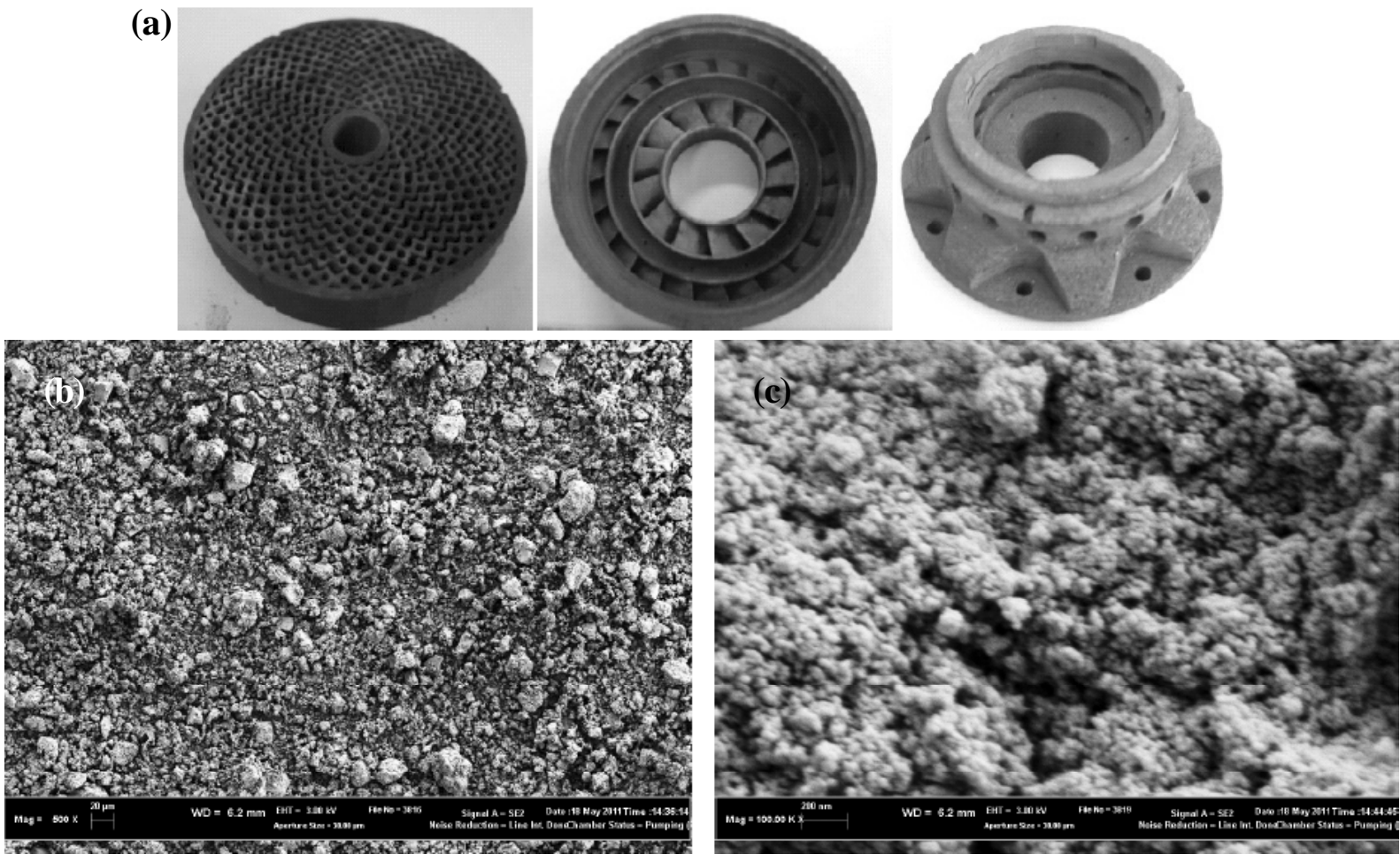

Fig. 1. (a) Photos of the parts of ceramic microturbine manufactured by AT, typical linear dimensions of the units are 3-5 cm; (b) SEM data on ceramics microstructure. Reprinted with permission from J. Timonen, M. Myllys, V. G. Konakov, A. V. Soudarev and I. Yu. Archakov, Structure of a ceramic material developed by laser prototyping techniques, Reviews on Advanced Materials Science vol 29 (2011) pp 175-179.

problems for all technique modifications; so, there is a real need in the approaches bridging this gap. One of such approaches will be considered below.

\section{CHEMICAL IMPREGNATION AS A PERSPECTIVE APPROACH TO DECREASE THE POROSITY OF THE CERAMIC UNITS MANFACTURED BY ADDITIVE TECHNOLOGY}

The approach based on the chemical impregnation technique was developed to decrease the material porosity. It has been shown that it provides a possibility to minimize material porosity and to increase the mechanical properties of the AT produced ceramic units in a wide temperature range from room temperature (RT) up to working temperature of ceramic microturbines [20] $1100^{\circ} \mathrm{C}$.

\subsection{Details of Ceramic Units Manufacturing, Impregnation Procedure, and Measurement Technique}

As it was mentioned in Introduction section, Selective Laser Melting (SLM) was used to produce metal-ceram- ics ("green-detail") from the raw metal-ceramic powder composition based on Al-SiC-B-BN (In, Ga) system, the details of the approach could be found in [12-17]. In this work, we've tested the ceramic units produced using Phenix PM-100 device modified for metal-ceramic raw materials; some revisions in powder aligning/compacting and surface leveling unit were introduced in the device, the most important revision was the change of metal blade to ceramic roller.

The procedure of chemical impregnation was as follows: porous material was impregnated by tetraethoxysilane and subjected to alkaline hydrolysis by $1 \mathrm{M}$ ammonia aqueous solution for 10 hours. As a result, $\mathrm{SiO}_{2}$ gel was formed in the ceramic unit pores. At the next step, the ceramics was dried at room temperature for 12 hours. It should be noted that the resulting silica gel structure is generally sponge-like. Following [21-23], alkaline hydrolysis was chosen since the duration of the process (see data on equilibrium constants in Refs. [21-23]) here was rather long; in turn, this resulted in the complete pores filling.

The dried ceramics was treated by the mixture of $1 \mathrm{M}$ $\mathrm{Al}\left(\mathrm{NO}_{3}\right)_{3} / 1 \mathrm{M} \mathrm{Mg}\left(\mathrm{NO}_{3}\right)_{2}$ aqueous solutions for 20 hours (obviously, the process duration depends on the thickness of ceramic unit, the time mentioned was used to provide impregnation of ceramic microturbine parts with 

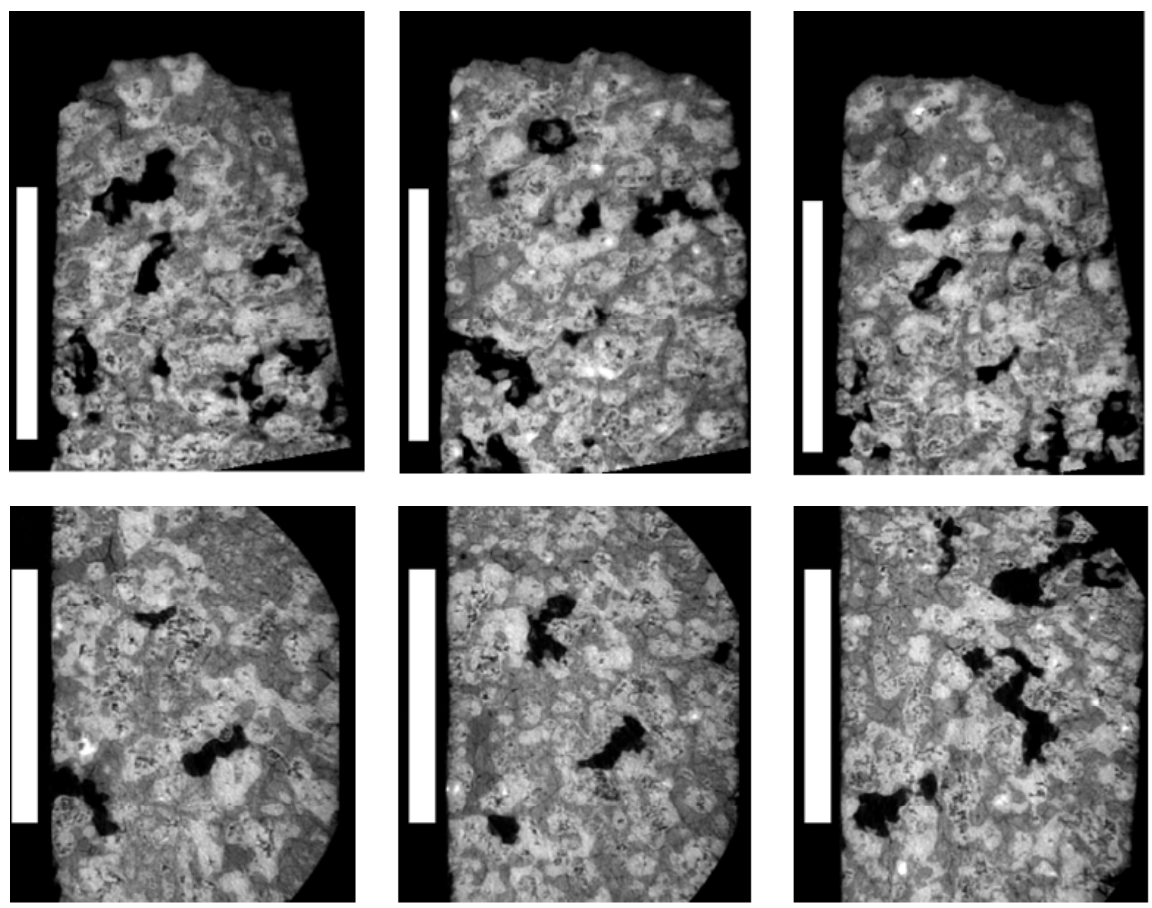

Fig. 2. Material porosity characterization according to X-ray tomography data (Xradia MicroCT-400, $E_{\max }=40 \mathrm{keV}$ ): upper line - "side-to-side" scanning, bottom line "top - down" scanning; the scale bar is $500 \mu \mathrm{m}$.

typical linear dimensions of 3-5 cm). Al/Mg-impregnated units were dried at $100-110^{\circ} \mathrm{C}$ for 24 hours, as a result, the sponge-like gel structure transformed into a globular one. The final treatment step was the high-temperature calcinations at $950{ }^{\circ} \mathrm{C}$ for 12 hours providing alumosilicate $\left(2 \mathrm{Al}_{2} \mathrm{O}_{3} 2 \mathrm{MgO}_{5} \mathrm{SiO}_{2}\right)$ formation with the structure similar to cordierite one.

A set of approaches was used to investigate the material properties. Pore size analysis was carried out using Nova 1200e (Quantachrome). The material porosity was calculated from the results of hydrostatic weighing. The details of X-ray tomography (Xradia MicroCT$400, E_{\max }=40 \mathrm{keV}$ ) were reported in [19]. Gel and cordierite microstructures were characterized using optical microscopy (OM, METAM, LOMO) and scanning electron microscopy (SEM, Zeiss Supra V-55). X-ray diffraction patterns (XRD, SHIMADZU XRD-6000, Cu-K $\alpha$ at $\lambda=1.54 \AA$ ) were analyzed to clarify the structure of alumosilicate grown in the ceramic units pores. Mechanical properties (ultimate bending stress) were measured according the standard procedures via three-point method.

\subsection{Material Structure and Mechanical Properties}

Parts of ceramic microturbine manufactured by AT (laser prototyping) technique are shown in Fig. 1a, Fig 1b demonstrates SEM data on ceramics microstructure. More information on ceramics porosity can be seen in
Fig. 2 demonstrating data obtained by X-ray tomography. The upper line in Fig. 2 presents typical ceramics structures taken during "side-to-side" scanning, while the bottom line shows typical results of "top-to-bottom" scanning. Gray regions in these images are attributed to ceramics and black regions are pores. As seen from Fig. 2, significant porosity is observed in the material; generally, a limited number of big-size pores (up to microns) presents in the material bulk. The results of pore size analysis both from X-ray tomography and nitrogen adsorption (Nova 1200e) provides the integral porosity estimate as $\sim 30 \%$. As it was discussed in Introduction Section, this value is quite high for the ceramic microturbine and there is a vital necessity to decrease it. Hence, the approach providing cordierite structures possessing $\AA$-size pores seems to be quite reasonable.

Figs. $3 \mathrm{a}$ and $3 \mathrm{~b}$ depict the sample surface before and after the impregnation process, the structure of the cordierite grown in the ceramic material pores is shown in Fig 3c. The analysis of X-ray diffraction patterns prove that the ceramics grown in the sample pores is quite similar to cordierite. As can be seen from the figure, the effect of the surface pores curing (surface smoothing) is evident.

Fig. 4 demonstrates the decrease in the sample porosity and the increase in the ceramics density as a function of the impregnation cycles number. As seen from the figure, first and second impregnation inputs prevail in the material porosity decrease; the first impregnation eliminates $\sim 40 \%$ of the initial porosity, the second one 

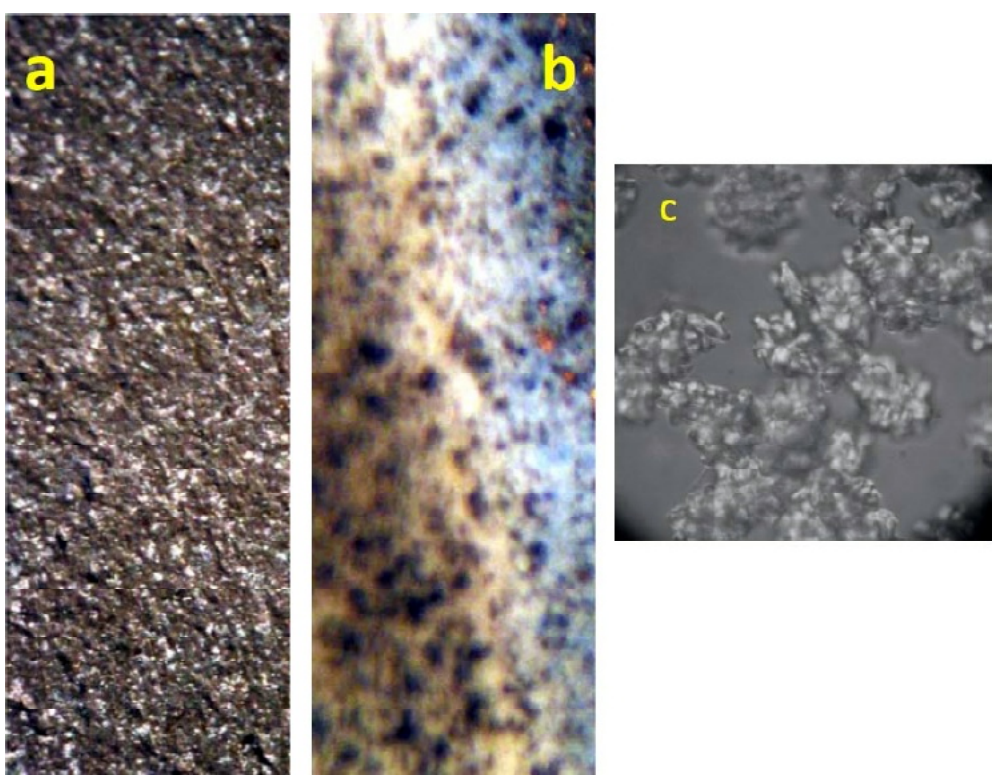

Fig. 3. The photo of the ceramic unit wall surface (optical microscopy at x125): (a) before impregnation and (b) after impregnation; (c) cordierite structure grown in the materials pores.

is twice less effective. These two impregnation cycles provided the porosity decrease from $30 \%$ down to $12 \%$. The following impregnation cycles provided porosity decrease down to 5-7\%, this value seems to be the maximal one since additional impregnation shows negligible results. This porosity decrease is accompanied by the ceramics density increase from 2.1 to $2.7 \mathrm{~g} / \mathrm{cm}^{3}$. Obviously, the direct computation of this effect is rather complicated, but the estimates performed according [24] give an opportunity to assume that the cordierite structure growth occurred uniformly in the pores in whole sample bulk; the effect of cordierite growth in the surface layer only could not affect material density in such a way.

The results of the ultimate bending tests (each measurement is averaged on the results of 10 samples test) are presented in Fig. 5 - the positive impregnation effect is evident: indeed, the porosity decrease provides the increase in the ceramics bending stress from 40 to 60 $\mathrm{MPa}$, moreover, this increase is observed in the wide temperature range up to $1100^{\circ} \mathrm{C}$.

\section{CONCLUDING REMARKS}

The analysis of current approaches used to fabricate ceramic products by Additive Technologies, in particular, approaches based on the Selective Laser melting method demonstrates that these technologies are at the R@D step now. A number of scientific and technical problems should be solved to provide their wide use in industry; these problems are not caused by technology, but are due to the nature of the ceramic materials. A number of these problems can be solved within the ap-

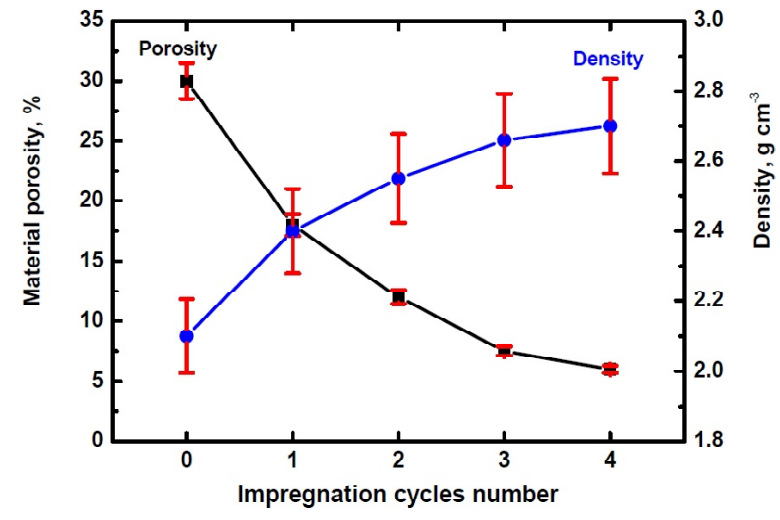

Fig. 4. Impregnation results: the changes in materials porosity and ceramics density (measurements accuracy $7 \%$ ).

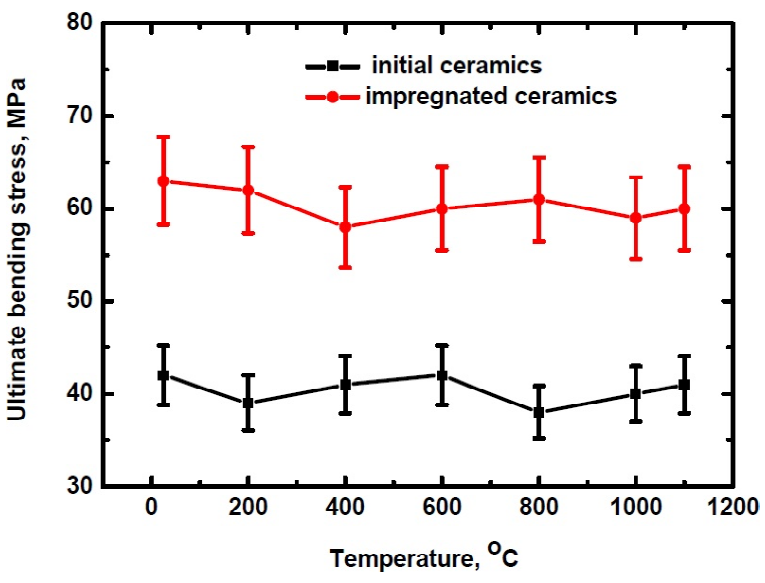

Fig. 5. Impregnation results: the comparison of ultimate bending stress for the initial ceramics and the same materials after 4 impregnation cycles, the accuracy of the measurements was $\pm 10 \%$. 
proaches discussed; however, the final product porosity decrease seems to be common task in all of them.

As an example of possible decision of this problem, chemical impregnation was tested to decrease the porosity in the ceramic units produced by additive technology (laser prototyping). Cordierite-like structures were grown in the micron-sized pores of the material; these grown ceramics possessing $\AA$-size pores uniformely filled the pores of the initial material. As a result, the ceramics porosity was decreased from $30 \%$ to $5-7 \%$ and the material density was increased from 2.1 to $2.7 \mathrm{~g} /$ $\mathrm{cm}^{3}$. In turn, the porosity decrease and the increase in material density resulted in significant improvement of the material mechanical properties: the ultimate bending stress was increased from 40 to $60 \mathrm{MPa}$, these values were shown to be constant in a wide temperature range from room temperature up to $1100{ }^{\circ} \mathrm{C}$.

\section{REFERENCES}

[1] David L. Bourell, Perspectives on Additive Manufacturing, Annual Review of Materials Research, 2016, vol. 46 pp. 1-18. https://doi.org/ 10.1146/annurev-matsci-070115-031606

[2] W.J. Sames, F.A. List, S. Pannala, R.R. Dehoff, and S.S. Babu, The Metallurgy and Processing Science of Metal Additive Manufacturing, International Materials Reviews, 2016, vol. 61, no. 5, pp. 315-360. https://doi.org/10.1080/ 09506608.2015.1116649[3] X. Tian, D. Li, and J. G. Heinrich, Rapid Prototyping of porcelain products by layer-wise slurry deposition (LSD) and direct laser sintering, Rapid Prototyping Journal, 2012, vol. 18, no. 5, pp. 362-373. https:// doi.org/10.1108/13552541211250364

[4] Thomas Muhler, Jurgen Heinrich, Cynthia M. Gomes, and Jens Gunster, Slurry-based Additive Manufacturing of Ceramics, International Journal of Applied Ceramics Technology, 2013, vol. 12, no. 1, pp. 1-8. https:// doi.org/10.1111/ijac.12113

[5] Ch. W. Hull, Method For Production Of Threedimensional Objects By Stereolithography, US Patent US 5174943A, 1992. https:// patents.google.com/patent/US5762856A/en

[6] T. Chartier, C. Dupas, M. Lasgorceix, J. Brie, N. Delhote, and Chr. Chaput, Additive Manufacturing to Produce Complex 3D Ceramic Parts, The Journal of Ceramic Science and Technology, 2015, vol. 6, no. 2, pp. 95-104. https:// doi.org/10.4416/JCST2014-00040

[7] B.Derby, Inkjet printing ceramics: From drops to solid, Journal of the European Ceramic Society,
2011, vol. 31, no. 14, pp. 2543-255. https://doi.org/ 10.1016/j.jeurceramsoc.2011.01.016

[8] C.Hinczewski, S.Corbel, and T.Chartier, Ceramic suspensions suitable for stereolithography, Journal of the European Ceramic Society, 1998, vol.18, no. 6, pp. 583-590. https://doi.org/10.1016/ S0955-2219(97)00186-6

[9] J. W. Halloran, V. Tomeckova, S. Gentry, S. Das, P. Cilino, D. Yuan, R. Guo, A. Rudraraju, P. Shao, T.Wu, T. R. Alabi, W. Baker, D. Legdzina, D. Wolski, W. R. Zimbeck, and D. Long, Photopolymerization of powder suspensions for shaping ceramics, Journal of the European Ceramic Society, 2011, vol. 31, no. 14, pp. 26132619. https://doi.org/10.1016/ j.jeurceramsoc.2010.12.003

[10] Dongdong Gu, Yves-Christian Hagedorn, Wilhelm Meiners, Konrad Wissenbach, and Reinhart Poprawe, Selective Laser Melting of in-situ TiC/ $\mathrm{Ti}_{5} \mathrm{Si}_{3}$ composites with novel reinforcement architecture and elevated performance, Surface \& Coatings Technology, 2011, vol. 205, no. 10, pp. 3285-3292. https://doi.org/10.1016/ j.surfcoat.2010.11.051

[11] Jan Wilkes, Yves Christian Hagedorn, Sörn Ocylok, Wilhelm Meiners, and Konrad Wissenbach, Rapid Manufacturing of Ceramic Parts by Selective Laser Melting, In: Advanced Processing and Manufacturing Technologies for Structural and Multifunctional Materials, Part III, Ceramic Engineering and Science Proceedings, vol. 31, no. 8, pp 137-148. https:// doi.org/10.1002/9780470944066.ch13

[12] A.V. Soudarev, V.G. Konakov, N.F. Morozov, I.A. Ovidko, and B.N. Semenov, In: Proceedings of GT2008, 2008 ASME Turbo Expo Power for Land, Sea\& Air (Berlin, Germany, June 9-13, 2008, GT2008-50549), CD N200. https://doi.org/10.1115/ GT2008-50549

[13] A.V. Sudarev,A.S. Molchanov, A.A. Surjaninov, and V.G. Konakov, In: Proc. III Int. Conference Engines for Aircrafts in XXI century (TSIAM, Moscow, 2010), p. 393, In Russian.

[14] A.V. Sudarev, V.G. Konakov, and P. Avran, Procede de fabrication d'une poudre metal-ceramique appropriee pour la fabrication d'une piece de ceramique dure et procede de fabrication correspondant, Demande de brevet d'invention, FR20160054195 20160511, 2017-11-17.

[15] V.G. Konakov, E.N. Solovyeva, I.Yu. Archakov, and S.N. Golubev, Strength of $\mathrm{Al}_{2} \mathrm{O}_{3}-\mathrm{SiC}-\mathrm{BN}$ $\mathrm{Si}_{3} \mathrm{~N}_{4}$-based ceramics, Materials Physics and Mechanics, 2013, vol. 18, no. 1, pp. 93-100. 
http://www.ipme.ru/e-journals/MPM/no_11813/ MPM118_11_konakov.pdf

[16] V.G. Konakov, A.V. Sudarev, N.F. Morozov and I.A. Ovid'ko, An approach to produce nonshrinkable ceramic construction unit, Russian patent Ru 2399601, November 19, 2008.

[17] V.G. Konakov, I.A. Ovid'ko, and B.N. Semenov, An approach to produce non-shrinkable nanomodified ceramic construction unit, Russian patent Ru 542073, December 26, 2013.

[18] S.R. Stock, MicroComputed Tomography: Methodology and Applications (CRC Press Boca Raton, 2008).

[19] J. Timonen, M. Myllys, V. G. Konakov, A. V. Soudarev, and I. Yu. Archakov, Structure of a ceramic material developed by laser prototyping techniques, Reviews on Advanced Materials Science, 2011, vol. 29, no. 2, pp. 175179. http://www.ipme.ru/e-journals/RAMS/ no_22911/10_timonen.pdf

[20] Y. Chivel, A. Sudarev and V. Konakov, Additive manufacturing technology of ceramic turbomachines, conference paper in World PM2016 Proceedings: AM - Special Aspects in
AM Technology (Hamburg; Germany; 9 - 13 October 2016); ISBN: 9781899072484 . https:// www.epma.com/publications/euro-pmproceedings/product/world-pm2016-am-specialaspects-in-am-technology

[21] K.D. Keefer, Silicon Based Polymer Science: A Comprehensive Resource; In: Better Ceramics Through Chemistry II (Springer, 1984), pp.15 - 24. https://www.amazon.com/Silicon-Based-PolymerScience-Comprehensive-Chemistry/dp/ 0841215464

[22] E. R. Pohl and F. D. Osterholtz, Kinetics and Mechanism of Aqueous Hydrolysis and Condensation of Alkyltrialkoxysilanes, In: Molecular Characterization of Composite Interfaces, ed. by H. Ishida and G. Kumar (Plenum, New York. 1985), pp. 157-170. https://doi.org/10.1007/978-3-662-29084-2_10

[23] R. Aelion, A. Loebel, and F. Eirich, Hydrolysis of ethyl silicate, J. Am. Chem. Soc., 1950, vol. 72, pp. 5705-5712. https://doi.org/10.1021/ja01168a090

[24] A.A. Appen, Glass Chemistry (Khimiya, Leningrad, USSR, 1974), In Russian. 